\title{
Leadership in higher education: training specialists in humanitarian technologies
}

\author{
Valeriy Zarubin \\ Herzen State Pedagogical University of Russia \\ 48 Moyka Emb., 191186, Saint Petersburg \\ Russian Federation \\ e-mail: vg_zarubin@mail.ru \\ Anastasia Semenova \\ Herzen State Pedagogical University of Russia \\ 48 Moyka Emb., 191186, Saint Petersburg \\ Russian Federation \\ e-mail: semyonovaa@mail.ru
}

\begin{abstract}
Our paper analyzes the important and timely issue of training specialists in humanitarian technologies as a special case of fostering leadership in higher education.

We investigate various alternative meanings of the concept of "humanitarian technologies" in higher education, as well as provide an insight and experience from sociological studies of the processes of developing new and popular vocational education programs by the university. The results and outcomes of our research appear to justify the need to design new professions for leaders who would be able to face and to solve real social contradictions of non-standard and outstanding business, social and production situations in their daily professional lives.

Moreover, the stages of designing a new profession of a humanitarian technologist are revealed within the framework of the research. Based on the principles of the competence approach, we created a model of qualification requirements for a specialist in the field of humanitarian technologies. Our results might be relevant for higher educational professionals and stakeholders.
\end{abstract}

\section{Introduction}

Our paper highlights the experience of sociological study of the development processes of a university behavior strategy on the local labor market and interaction with its subjects. The subject of such a strategy is not only the provision of high-quality education, but also the development of new vocational and educational programs that are in demand in public practice (see e.g. Hutmacher 1996; Koudelková and Svobodová 2014; Rybakova and Fomina 2015; Jankelová et al. 2017; Bordean and Sonea 2018; Thackwell et al. 2018; or Naushad 2018). The paper contemplates about developing and constructing new professions designed to solve the real social contradictions of not so standard production situations (OECD 2018).

Nowadays, hardly anyone besides the university is able to solve such a crucial task, and this type of the university's activity becomes an object of sociological study. The construction of an innovative training program for specialists with higher education in the field of humanitarian technology includes four stages. The first is the theoretical justification of the professional field, the second is the building of a model of professional competencies, the third is the interaction of the university with a competent expert community, and the fourth is the creation of such an innovative educational program that will properly provide training for a specialist in a new professional field. An integral attribute of all stages is the operational sociological support of this 'design' activity.

Let us dwell a little more on the distinction between the concepts of 'interdisciplinary approach' and 'integration'. Interdisciplinary means the participation of many parts in a process, with parity participation. As a rule, one of the disciplines becomes the leader, setting the algorithms and the share of meaningful participation for others. Integration assumes interaction of various on a common basis.

Thence, in the integration interaction of the disciplines of the curriculum, the overall goal is a specific range of competences assigned by the module. For example, for an invariant module, it is the creation of a holistic humanitarian picture of the world by the joint efforts of all five training courses, oriented toward the acquisition of basic, universal competencies of understanding and constructing models of socio-humanitarian processes by the student. 


\section{Literature review}

One might ask herself or himself: what content is included in the concept of 'humanitarian technology'? There are various interpretations of the concept of 'humanitarian technology': the technology of creating, changing and processing the framework and rules of human behavior, production, packaging and implementation of meanings; technologies aimed at the development of the human personality and the creation of appropriate moral and ethical norms, ways of developing intellectual potential and physical condition (Al-Haddad and Kotnour 2015; Strielkowski 2018). There is an opinion that the algorithm of these technologies does not have unambiguous definitions, but it is indispensable without humanitarian technologies.

Some researchers refer humanitarian technologies mainly to the political sphere and oppose them to power coercive functions. Humanitarian technologies have nothing to do with moralizing and confronting good and evil (Zarubin and Semenova 2017). The heuristic potential of the concept of 'humanitarian technologies' manifests itself against the background of the 'social technologies' concept. Humanitarian technologies can be a variety of social technologies (Bobkova et al. 2015). They also act as systems of scientific knowledge, the use of which makes it possible to realize a specific social plan through certain conditions, means and methods (Abdulgalimov 2014).

The usual phrase 'social and humanitarian' at the societal level leads to the problems of popular nowadays theories of the civil level. It is both within the framework of the 'state-civil' dichotomy and within the framework of the 'political - economic - civil' trichotomy. In any case, we are talking about the development of public infrastructure, consisting of non-governmental and non-profit groups and organizations.

The term 'social technologies' arose earlier, perhaps in the context of the theory of 'social engineering' of Karl Popper, and has already taken root in sociology (Blomgren 2017). Social technologies are often realized through specialties related to social work, mainly to its manipulative side, defined by the 'subject-object' relationship. From the sociological point of view, such technologies can be represented as a functional system or a set of sequential operations, procedures for targeted impact and implementation of previously prepared plans (programs, projects) and obtaining the optimal social result. Social technologies are ultrathin technologies, caused by a multitude of biological, psychological and social factors, the nature of which is not sufficiently known. That is why total social profiling technology seems to be impossible (see e.g. Ignatyeva 2015).

The study of humanitarian technologies is based on the denial of manipulation by people, and the emphasis is on the transition from a mobilized industrial society to a modern information society. The subjectsubject relations become the subject of such technologies, and the habitual problem associated with the object of education is receding into the background. As the state lost its monopoly position in this market, new structures began to be formed that had financial, administrative, material and intellectual resources for the production of the sense of political, managerial, economic, scientific, and sociocultural activity, most of them in the shadows of the Internet and even Darknet (Strielkowski 2017). This is very relevant since these processes foster the creation of leadership in higher education (Sturm et al. 2017).

The designing of a new profession involving humanitarian technologies is carried out on the basis of a competence approach that originates in the theories of speech communication, management sociology and social psychology of the early $20^{\text {th }}$ century (see e.g. Emerson 1976; or Taylor 2010). It was subsequently developed in sociological theories of modern times (see e.g. Raven 1984; or Giddens 1987) and finds application in branch sociological theories - the sociology of youth, education, professions, etc. The concept of 'competence' includes the reflective attitude of the actor to reality, pointing to the complexity of the 'producer of practices' phenomenon - a social subject.

\section{Four stages of educational programs for training specialists}

The first stage of construction is the theoretical justification of the future technology professional field. It, due to novelty and complexity, deserves a thorough conversation. Humanitarian technologies are a new direction of professional education, designed to draw the potential of modern humanities into the channel of professional needs of workers, to enrich the specialist with missing skills in the field of information and communication, organizational and managerial activities, as well as activities focused on multicultural and multiethnic interaction. The phrase 'humanitarian technology' is very popular these days. In the country, agencies in the field of humanitarian technologies are increasingly active. Humanitarian technologies are the field of systematization, co-organization and ordering in space and time of components of purposeful collective activity of people on the basis of modern humanitarian knowledge. The components of humanitarian technologies are intangible elements, including knowledge, ideas, sign environment. Humanitarian technologies are resource-intensive technologies, where the resource is understood as: ideas and concepts that are transformed into activities, goals and projects; people who are able to develop and implement development projects and programs; financial and material funds for the implementation of technology. 
The core of humanitarian technologies is information that allows to 'squeeze' time. In place of routine mental operations come active and more complex types of thought-reflexive activity - conceptualization, goalsetting, counseling. The information allows to 'technologize' time and fix the obtained intermediate results and products of humanitarian activity, and also to use them in other systems of activity. All this leads to the emergence of more and more variety of humanitarian technologies, for example, counseling, expertise, regulation of relations in information exchange processes.

Humanitarian technologies are infrastructural, non-linear. Uncertain factors may act in each link of the technological chain. The recognition of non-linearity is important for the development of competence models and training programs for relevant specialists.

If physical technologies are related to the objective capabilities of the material environment, the humanities are responsible for the subjective factor that translates some possible future into reality. The former form a space of trends, while the latter manage the realization of these trends. In practice, humanitarian technologies are used, for example, by businessmen to manage the enterprise and the state - to solve their problems. All human activity, minus material production, can be entered into the category of humanitarian technologies. These technologies, including the analysis of the future, cannot be put on the pipeline, adapted to obtain a standard result, and this is in contrast to conventional, mechanical or physical technologies.

The base for humanitarian technologies is the recognition of the unity between an individual and society. The technology that controls the personality is realized in the context of a social group and society. This, on the one hand, has a strong impact on the individual, and on the other - a direct or indirect effect on society.

The tendency to individualize life is growing and the need for communication is growing in the information society. Humanistic communication technologies are replacing the manipulative social technologies. Humanitarian technologies solve, on the one hand, the problem of self-realization of a person or a group and, on the other hand, the problem of developing communication in the framework of a communicative strategy.

In the context of humanitarian technologies, a person acts as a peculiar sign system, highly informative and open to contacts, which facilitates the actualization of individual-personal senses acting as a transformative beginning. The specificity of humanitarian communication technologies is in their belonging to the existential or ethical content of the action. They depend - to the greatest extent - on the humanitarian content of communicative practice, otherwise they are just technologies of social manipulation. Humanitarian technologies presuppose feedback, dialogue, communication between participants in the communicative process.

When it comes to the impact on the individual, it makes sense to talk about humanitarian technologies, and the impact on social communities of any scale is more appropriately to be called social technologies. But often the same impacts can be attributed to both humanitarian and social technologies. Adjective 'humanitarian' can have two meanings: attribution to the humanities, to humanitarian knowledge, and a focus on the individual. Humanitarian technologies can be understood as modern forms of existence and functioning of humanitarian knowledge.

The diversity, typology and novelty of humanitarian technologies will still be the subject of social and theoretical analysis. To discuss this problem, it is first necessary to build a detailed idea of what such technologies are and only then - to search for their historical roots and analyze the correlation of history and modernity in the humanitarian technologies. Nowadays, these technologies simply cannot avoid bearing the specific 'timing features'. Their effective use and wide distribution is largely due to the information needs of society. Consequently, the result of professional training can be described with the help of the concept of 'professional competence'. For example, "professional competence of a teacher means an integral characteristic that determines the ability of a specialist to solve professional problems and typical professional tasks arising in real situations of professional activity, using knowledge, professional and life experience, values and inclinations." 'Ability' is understood not as 'predisposition', but as 'skill'. Abilities are individual psychological qualities of a person, allowing to successfully perform a certain type of activity.

Secondly, competence is manifested in activities, therefore it is impossible to 'see' undeveloped competence. Professional competence of the teacher is manifested when solving professional tasks.

Thirdly, it is of fundamental importance that in what proportion different types of competences are acting in a single professional competence - key, basic and special ones.

In addition, the competence approach requires disclosure of the content of tasks that reflect the basic competence. On the example of a modern teacher, these are: the ability to see a student in the educational process; to build an educational process with a focus on the goals of a particular level of education; to establish interactions with other subjects of the educational process, school partners; create and use an educational environment for educational purposes; design and implement professional self-education. The above pedagogical concept represents methodological interest and heuristic potential in the field of designing new professions.

The second stage of construction is the construction of a model of professional competencies. Based on the principles of the competence approach, a model of qualification requirements for a specialist in humanitarian technologies was created. To a certain extent, these requirements were dependent on the quality of the measurement 
scales of the study. As a result, the basic scales of the model of the humanitarian technologist professional competencies are grouped into six groups (descriptors).

The model of professional competence of a humanitarian technologist includes 6 descriptors and 51 kinds of specific competencies. The method of designing scales is expert (nomination generation and selection). Relevance of the result is confirmed empirically: the availability of tools in the survey, the lack of significant additions, a high level of comparability with other developments. In this sense, the model of professional competence is the basis for creating a new specialty. Modeling, as one of the types of design, leads to the emergence of an entirely new task in the sphere of higher professional education - the need to prepare pedagogical staff capable of working in conditions of competition of educational institutions that can create competitive advantages and predict the situation in labor markets and educational services.

The third stage of construction is the interaction of the university with the competent expert community. In modern marketing, it is well known that a successful product can be developed based on the study of the needs of future consumers. To determine the relevance of the new specialty in the labor market, two expert communities were formed. The first included a real sector of public production, services and information: employers engaged in the sphere of material production; in state, regional, municipal government bodies, in nonprofit and public organizations (political parties), in the sphere of social security, public health, medicine; in the sphere of culture, science, education; in the sphere of services (trade, finance, advertising, marketing, IT, etc.); in mass media. The second community represented the education sector and included heads of general, primary and additional education institutions. The expert communities were not represented by random sets of specialists, but by groups of employers interested in long-term cooperation with the university. The construction of a new profession as a process is woven into the real fabric of partnership between the university and employers. This partnership as an element of feedback involves a dialogical search for answers to the questions: what qualifications should the future specialist-the graduate of the university-be responsible for? In what spheres of public production and professional situations will the graduate be in demand? Will the graduate survive in conditions of competition in the labor market, in competition with graduates of previous years and other profiles? In the realities of this partnership, deterrent barriers are discovered that require consideration and overcoming for the sake of partnership success. So, the first barrier is the existence of the opinion that the relationship between the employer and the university should be built unilaterally. The employer appears in the form of a sponsor, patron of arts, and the university - in the role of a poor relative or a grateful freeloader. The results of the expert survey showed that employers are trying to build a partnership with universities in a different way (the survey of 501 employers was conducted in Saint Petersburg in 2017, the array is close to the proportions of the industrial structure of the employed population of the city). Employers in the segment of large and medium-sized corporations have little interest in such forms of partnership that the institution of higher education is offers as a provider of future specialists (see Table 1).

Table 1. Least attractive forms of partnerships for employers with the university, preparing future specialists $(n=501)$

\begin{tabular}{|l|l|}
\hline Forms of cooperation between the university and employers & $\%$ \\
\hline Financing of targeted training of specialists at the university & 2,8 \\
\hline Development of the criteria for the quality of education at the university & 1,9 \\
\hline Development, examination of educational programs of the university & 1,4 \\
\hline Providing financial support to the university & 0,4 \\
\hline
\end{tabular}

Source: Own results

In other words, the employer seeks to avoid the burdensome, costly and sometimes ungrateful role of the sponsor, but is much more willing to act as a partner, and above all, as a base for the professional training of future specialists (see Table 2).

Table 2. The most attractive forms of partnership for employers with the university, preparing future specialists $(\mathrm{n}=501)$

\begin{tabular}{|l|l|}
\hline Forms of cooperation between the university and employers & $\%$ \\
\hline Organizing student production practices & 86,7 \\
\hline $\begin{array}{l}\text { Signing contracts to carry out research within the framework of students' } \\
\text { final qualification works }\end{array}$ & 34,6 \\
\hline Participation in the educational process as teachers & 27,5 \\
\hline Participation in joint research and development projects & 25,6 \\
\hline Corporate educational programs on the basis of the university & 14,7 \\
\hline
\end{tabular}

Source: Own results 
An important characteristic of most employers is their comparatively high intellectual level, modern knowledge and, on this basis, the willingness to actively engage in joint research and in the teaching process. However, the theoretical (conceptual) strata of professional knowledge still cause difficulties for many managers in the real economy (see Table 3).

Table 3. The most attractive forms of partnerships for employers with the university, preparing future specialists $(\mathrm{n}=501)$

\begin{tabular}{|l|l|}
\hline Forms of cooperation between the university and employers & $\%$ \\
\hline Development of own educational structures & 4,3 \\
\hline Development of control tasks, tests & 3,8 \\
\hline
\end{tabular}

Source: Own results

Thus, in modern conditions there is a need to form a new type of relations between universities and employers, and one of its priorities should be the involvement of the latter in the development and implementation of the educational policy of the university.

The second barrier is the lack of understanding among employers of those qualitative changes that occur in higher education. The managers or businessmen still remember how they received the diploma of a specialist, while the two-level model of higher education is becoming more widespread. the terms 'two-level education system', 'bachelor', 'master' for many of them sound almost as from the story of Harry Potter, and not from real life, which indicates a significant lag in information on the modernization of higher education (see Table 4). A survey of 414 employers was conducted in Saint Petersburg in 2017, including 212 from the real sector, services and information, and 202 from educational institutions.

Table 4. Answers of employers to the question: "To what extent are the opportunities for the future employee of the qualification stages of a bachelor's, specialist's, master's degree understandable for the you?", \%

\begin{tabular}{|l|l|l|l|}
\hline \multicolumn{2}{l}{$(\mathrm{n}=414)}$. \\
\hline Options to answer & Bachelor & Specialist & Master \\
\hline Completely clear & 35,6 & 56,5 & 24,1 \\
\hline Basically, they are clear & 23,7 & 27,0 & 23,6 \\
\hline Basically, not clear & 20,5 & 10,0 & 28,2 \\
\hline Completely unclear & 9,3 & 2,5 & 11,8 \\
\hline Difficult to answer & 10,8 & 4,0 & 12,3 \\
\hline
\end{tabular}

Source: Own results

Most employers represent the capabilities of specialists, and only about half are familiar with the capabilities of bachelors and masters. This means that the Russian labor market in the megalopolis is not quite ready for the transition of higher education institutions to two-level training, and the model of a specialist remains more familiar, while the concepts of 'bachelor' and 'master' remain unclear after a decade since the introduction of the Bologna process. Perhaps the problem is to establish the adequacy of these models to the specifics of jobs, but it is also obvious that employers do not understand the concept of a two-level system that is focused on enhancing the dynamism and flexibility of training in the realities of the labor market.

The third barrier is associated with a strong orientation of higher education institutions to prepare graduates for the most popular areas among applicants. This popularity is often stereotypical and inadequate to the needs of the labor market, partly contrary to the interests of society, the family, and especially - employers. In response to the request of applicants there is a certain skew in the structure of educational programs and contingent in favor of specialties in economics, management, law and information technologies, which complicates the structural contradictions of the labor market. The specificity of the labor market is the change in many professional fields and the formation of new types of employment. The understanding of the importance of the human factor is growing among employers. Oil, gas and high technology are rendered helpless before a storm of human problems. "How to resolve conflicts?", "How to keep your own Self?", "How to build your relationships at work and outside it?". 'Gazprom' and the stock market will not answer these questions. Here we need specialists of a different profile who have knowledge and are able to interact with people.

Competent approach focuses higher education on the activity component, the professionalization of training and the competitiveness of university graduates in the labor market. For the university, this means a radical restructuring of the mode of existence, involves profound system transformations affecting teaching, content, assessment, educational technologies, higher education links with other levels of vocational education. It is not enough to write down requirements for qualifications and competencies in program documents regulating 
the preparation of bachelors and masters. It is not enough to declare the principles of the framework agreement between the university and employers regarding employment placement - it is necessary that the students future professionals - took an active part in designing their own educational path.

The fourth stage of designing is the creation of an innovative educational program for the training of the new profession. As a result of the conceptual analysis carried out together with partners, such a program in the field of humanitarian technologies in the social sphere included 38 educational modules, grouped into four groups. At the heart of their typology is the criterion of combining the functional purpose of the module with the content of professional activity in humanitarian technologies.

In the first group - modules, focused on information and communication activities, servicing the educational process in terms of organizing information exchange and building stable links between social objects. The second group includes modules from the field of organizational and managerial activities, combining subject areas of economic knowledge, management and marketing, and servicing the educational process as a whole. The third - modules on social, political, religious and ethnic interactions, providing the formation and functioning of the foundations of civil society. The fourth group comprised modules related to activities in the field of health and social rehabilitation. In the fourth group, two sub-groups are distinguished. The first includes modules aimed at the technology of psychological care, and the second - the technology of prevention and rehabilitation in socio-crisis situations. All groups of modules are carried out through educational programs of bachelor and master's degree, advanced training, elective courses. For each module, a training and methodical complex has been developed. Thus, the training of a specialist in humanitarian technology fits into the framework of existing educational practices at a Russian university, including continuous professional education.

\section{Ratings of variable models based on expert assessments of employers}

Our analysis of the current state of the labor market in Saint Petersburg has revealed the following key problems related to the inconsistency of employers' requirements and the training of specialists by the higher education system:

- imbalance of labor supply and demand in the labor market;

- low competitiveness of young people who do not have a professional education, and those in need of social protection;

- inadequate development of in-house training of personnel, which impedes the growth of professional skills, mobility of the workforce and increases in frictional unemployment;

- backwardness of the personnel policy of most organizations, focused mainly on achieving current results, rather than on future development;

- $\quad$ lack of vacancies for young people who do not have work experience.

Where is the way out? It seems that a humanitarian specialist will be in demand in the labor market only if he/she is able to freely navigate in the world of people and knowledge (the ability to navigate) and build his/her own professional trajectory. He/she does not stop at what has been achieved, but is in constant search. His/her professional field is humanitarian technology.

The results of the sociological survey showed that, according to experts, employed in the real sector of social production, the specialists who had received educational training on the modules 'Technologies for extracting, processing and analyzing information', 'Reputation management technologies', 'Technologies of human interaction with high-tech information environment', 'Technologies of intellectual communications', 'Technologies of public communication' will be widely claimed on the modern labor market. According to experts, specialists who have mastered such educational modules as 'Technologies of social orientation of a person in the global information space', 'Technologies of ensuring security (information, ecological, economic)', 'Technologies of psychological assistance in crisis and emergency situations', 'Health-protecting technologies in the social sphere', 'Technologies of moderation in the sphere of social interaction'.

\section{Operational sociological support of the project}

An integral attribute of designing a new profession is operative sociological support of the project. At the stage of designing the model, the efforts of sociologists were aimed at developing original methods, carrying out a series of complex studies, analyzing and generalizing empirical results. At the stage of forecasting and dissemination of the model, scientific and methodological recommendations were prepared and partners were searched for joint research. The scale and complexity of the innovation project required adequate methods and techniques for conducting research. As a result, the technology of operational sociological support of the project activity of the university community was developed. Sociological support of innovation is one of the tools of 
strategic management in the university community. Its goal is to create effective feedback between all the partners of the innovation project, and this is in contrast to other types of research, but its foundation has been and remains the fundamental ideas of sociology and conceptual developments in its various branches (sociology of education, sociology of youth, organizations, conflicts, etc.). Sociological support itself belongs to the class of humanitarian technologies. Its purpose is to receive (in a short time) information about the state and processes occurring in the university community and require adequate management influence. There are two limits in the activity of the sociologist: time and space. The first one synchronizes the research process with the adoption of an administrative decision and leads to the fact that sociological information serves as one of the links of such a decision. The second (spatial) defines those areas where sociological information flows are generated (target groups of the university staff responsible for the adoption and implementation of managerial decisions, relevant subjects in the surrounding social space - the city or the region).

Time and space constraints determine the specifics of the tasks of sociological support and the combination of quantitative and qualitative research strategies. The logic of research has the form of a technological chain: the formation of the goal - programming - the collection of information - processing and analysis of information - the resulting sociological document. We are talking about the study of social processes within the university and in its social environment. Sociological support in this project has given the university management system feedback and information channels, which were absolutely necessary due to the dynamism of university life, the complication of social processes both inside and outside the university. This accompaniment was aimed at creating conditions for team project activity in designing both competence models and educational modules in the field of humanitarian technologies.

Is there a need to design new professions? Undoubtedly, there is, since modern educational policies of states and universities declare the advanced nature of education and proves it in its best corporate models. Therefore, such design becomes one of the types of the permanent functional activity of the university and should be reflected in its functional and organizational structure, with the corresponding specialization of the university units as a corporation. In the practice of the institution the competences as professional qualities of a future specialist must exist in the form of the results of education. The results of education are the expected and measurable educational achievements of the student, who ascertain what the graduate student is able to do after the completion of the educational program. The university should take responsibility for achieving the results of education. In this sense, the results of education are not only a planned indicator, but also a technology that must be implemented effectively, with the least expenditure and with high social returns.

\section{Conclusions}

Thus, the first stage of construction is the theoretical justification of the professional field of the future technology. The second stage of construction is the construction of a professional competencies model. Based on the principles of the competence approach, a model of qualification requirements for a specialist in humanitarian technologies was created. As a result, the main scales of the professional competencies model of the humanities technologist are divided into six groups (descriptors): intellectual and communicative competencies; professional competence; social competence; competence of a multicultural society; competence in the information sphere; competence in the field of knowledge, education and self-education. The third stage of construction is the interaction of the university with the competent expert community. The fourth stage of designing is the creation of an innovative educational program for the training of the new profession. As a result of the conceptual analysis carried out together with partners, the program included 38 educational modules, gathered into four groups, in the field of humanitarian technologies in the social sphere.

In the world practice, it is the universities themselves who have to take on the formulation of 'self-order', asking the employer and checking the positions with the state controllers on which the graduate's suitability for future professional duties is determined. In Russia, the correlation of job descriptions and university requirements is a special problem. First of all, it is a matter of detailing the qualification requirements (professional standards) for the specialist. The general structure of the standards has a clear sequential scheme that determines the entire set of requirements for employees. And they contain a list of key skills and knowledge necessary to fulfill each of these job responsibilities. It is professional standards that should serve as a starting point in the education and training system, forming the basis for educational standards. The list of knowledge required in the standards for performing job duties can serve as a full-fledged basis for the development of curricula in higher education institutions. The document sets the 'bar' to which educational institutions and enterprises should strive for the preparation, retraining and advanced training of personnel.

The educational program of a humanitarian technologist can be represented in a sequence of solving three main tasks: to develop the ability to realize its responsible presence in the present, to form an adequate image of the world and a person in it in the student's mind; here technologies of intellectual self-reflection, cultural identification are used, personal 'I-consciousness' is actualized; to develop the ability to theoretically construct models of sociocultural processes in humanitarian research technologies, that is, to implement the system- 
complex methodology of social and humanitarian research; to teach the art of working with people, because education, production, economics, science and technology, as well as politics, law or journalism, are human affairs. Actually, the whole range of modules that are offered in the educational program for mastering in the selection algorithms can be located within the solution of these three problems, to orient the training courses on the development of all three groups of humanitarian technologies.

Researchers engaged in the design of specialties have to take into account the unprecedented level of awareness, education, multiple identity of a modern person, whose motivation is extremely complicated and unpredictable. But today exactly this kind of a person with such motivation is a producer of social and professional practices, including the future. In the transition periods of society the future does not come from somewhere with prepared properties, but is developed in the practices of human activity. That is why, following the awareness of the demands of the time, the educational paradigm has also changed. Today it supposes that the result of education is competence as a personally integrated result-a set of activity characteristics: practical, experiential, motivational-value and cognitive readiness to act in a certain professional sphere.

\section{References}

Abdulgalimov GL (2014) Progress of information society in Russia and deficit of staff potential. Life Science Journal 11(8):494-496.

Al-Haddad S, Kotnour T (2015) Integrating the organizational change literature: a model for successful change. Journal of Organizational Change Management 28(2):234-262. doi: 10.1108/JOCM-11-2013-0215

Blomgren R (2017) Social engineering and cultural policy-theoretical and empirical reflexions from Swedish cultural policy in a historical perspective. International Journal of Cultural Policy 1:1-15. doi: $10.1080 / 10286632.2017 .1284826$

Bobkova EY, Korobejnikova EV, Nelyubina EG, Likhman VA (2015) Pedagogical problems of effective training of specialists in international virtualization of economic industry. Mediterranean Journal of Social Sciences 6(3 S4):17-24. doi: 10.5901/mjss.2015.v6n3s4p17

Bordean ON, Sonea A (2018) Student satisfaction and perceived skills: any link to employability? Entrepreneurship and Sustainability Issues 6(1): 356-370. doi: 10.9770/jesi.2018.6.1(22)

Emerson RM (1976) Social exchange theory. Annual Review of Sociology 2(1):335-362. doi: 10.1146/annurev.so.02.080176.002003

Giddens A, Social theory and modern sociology, $1^{\text {st }}$ edn. (Stanford University Press, Stanford, 1987), 310 p.

Hutmacher W (1996) Key competencies for Europe, Report of the Symposium Berne, Switzerland, 27-30 March, Council for Cultural Co-operation (CDCC), Secondary Education for Europe, Strasburg. https://files.eric.ed.gov/fulltext/ED407717.pdf Accessed 28 Aug 2018

Ignatyeva I (2015) The Trend of Technologisation of Modern Education (the Use of Humanitarian Technologies). Procedia-Social and Behavioral Sciences 214:606-613. doi: 10.1016/j.sbspro.2015.11.766

Jankelová N, Jankurová A, Masár D (2017) Effective management and self-government: current trends. Czech Journal of Social Sciences, Business and Economics 6(2):21-31. doi: 10.24984/cjssbe.2017.6.2.3

Koudelková P, Svobodová P (2014) Knowledge creation \& sharing as essential determinants of SMEs innovation. International Economics Letters 3(1): 12-20. doi: 10.24984/iel.2014.3.1.3

Naushad M (2018) A study on the antecedents of entrepreneurial intentions among Saudi students. Entrepreneurship and Sustainability Issues 5(3):600-617. doi:10.9770/jesi.2018.5.3(14)

OECD (2018) Selection of key competencies. Executive Summary-DeSeCo Project Web http://www.oecd.org/education/skills-beyond-school/definitionandselectionofcompetenciesdeseco.htm Accessed 28 Aug 2018

Raven J, Competence in modern society: Its identification, development and release, $1^{\text {st }}$ edn. (HK Lewis, London, 1984), $259 \mathrm{p}$.

Rybakova AI, Fomina SN (2015) The model of professional training of specialists of social work in the conditions of multilevel education on the basis of integrative approach. Contemporary Problems of Social Work 1(3):55-61. doi: 10.17922/2412-5466-2015-1-3-55-61 
Strielkowski W (2018) A postdoc's purpose. Science 360(6384):27-27. doi: 10.1126/science.aat6008

Strielkowski W (2017) Will the rise of Sci-Hub pave the road for the subscription-based access to publishing databases? Information Development 33(5):540-542. doi: 10.1177/0266666917728674

Sturm RE, Vera D, Crossan M (2017) The entanglement of leader character and leader competence and its impact on performance. The Leadership Quarterly 28(3):349-366. doi: 10.1016/j.leaqua.2016.11.007

Taylor FW, The Principles of Scientific management, $1^{\text {st }}$ edn. (Nabu Press, Charleston, 2010), 148 p.

Thackwell N, Chiliza B, Swartz L (2018) Mentorship experiences during registrar training: Reflections of Black African specialists in the Western Cape. Race Ethnicity and Education 21(6):791-807. doi: $10.1080 / 13613324.2017 .1294572$

Zarubin VG, Semenova AA (2017) Sotsiologia upravlenia: konstruirovanie predmetnogo polya nauki [Sociology of management: construction of the subjective field of science]. Nauchnoe Mnenie: ekonomicheskie, yuridicheskie I sotsiologicheskye nauki 1:8-13. 